\title{
Social networks and quality of life of elderly persons: a review and critical analysis of literature
} Odília Maria Rocha Gouveia 1,2
Alice Delerue Matos
Maria Johanna Schouten ${ }^{1,4}$

Keywords: Elderly. Social Networking. Quality of Life. Well-Being. Review.

\footnotetext{
Universidade do Minho, Centro Interdisciplinar de Ciências Sociais, Pólo UMinho (CICS.NOVA. UMinho). Braga, Portugal.

2 Universidade do Minho, Centro de Estudos de Comunicação e Sociedade. Braga, Portugal.

3 Universidade do Minho, Instituto de Ciências Sociais, Departamento de Sociologia. Braga, Portugal.

4 Universidade da Beira Interior, Departamento de Sociologia. Covilhã, Portugal.
} 


\section{INTRODUCTION}

Social networks are considered to be an important determinant of the quality of life (QOL) of the elderly, notably by allowing them to deal with stressful environments or difficult life experiences1. They can, for example, enable elderly persons with reduced income and/or health problems to reduce the potential negative effects of such factors ${ }^{2}$, thus promoting the maintenance or elevation of the QOL of these individuals. However, although literature emphasizes the positive effects of social networks on well-being ${ }^{3-5}$, they can also have a negative effect on individuals ${ }^{6,7}$, when, for example, the elderly are maltreated by one or more elements of their social networks.

The present literature review is part of a $\mathrm{PhD}$ research project within the framework of the Survey of Health, Aging and Retirement in Europe (SHARE) project, focusing on the impact of social networks on the QOL of individuals aged 50 or over in mono-residential contexts in Portugal.

The concepts used in the present study are derived from its insertion SHARE, being those included in the database of the fourth wave of this longitudinal project, the data collection of which took place in 2010-2011 in 16 European countries. The characteristics of the social networks that were taken into account are their size (number of individuals in the social network); the type of relationship (relationship of friendship, family relationship, neighborhood relationship, among other types of relationship); the geographical proximity of the elements of the social network (geographical distance between the residence of the respondent and those of the members of their social network); the frequency of contact (frequency of face-to-face, telephone or other type of contact with elements of the social network); and emotional closeness (level of emotional closeness to network members).

Another important concept in this work is QOL, which is also included in this database. In the SHARE project, QOL is defined by the level of satisfaction of needs in the areas of control, autonomy, selfrealization, and pleasure. Since QOL is a measure of well-being, other welfare measures have been included in this literature review which refer to one or more dimensions of the concept of QOL.

This article aimed to review and critically analyze the literature on the relationship between the characteristics of the social networks of elderly persons on the one hand and their quality of life or other indicators of well-being on the other, in several European and North America countries. It also aimed to identify gaps in the level of scientific knowledge about this subject.

\section{METHOD \\ Procedure}

In order to identify the scientific publications to be included in this review and analysis, five search engines were used in order to allow access to the largest number of existing publications on the relationship under analysis: Web of Knowledge, Scopus, Scholar, Science Direct and Biblioteca do Conhecimento Online (Online Knowledge Library) (b-on). These search engines were selected due to their interdisciplinary nature, in order to cover several disciplines involved in aging and the relationship between social networks and QOL (or other indicators of well-being).

The following keywords were inserted in the search engines, in both the English and Portuguese languages: social networks; size of the social network; type of relationship; composition of the social network; geographical proximity of the social network; frequency of contact; emotional closeness; QOL; well-being; elderly persons; old age. In addition, the bibliographical references of articles found using these terms were consulted, in order to select references to further research into the subject related to the study.

The studies included in this integrative review were selected based on their content, the geographical context of the study and the date of publication. In terms of content, each publication selected for this literature review included results based on empirical data on the relationship of at least one of the social network characteristics already mentioned and QOL, 
or other indicators or measures of well-being in old age. Taking into account the purpose of this study, the possible influence of sociodemographic variables was not considered in this article. Regarding the second selection criterion, given that this literature review forms part of the European SHARE project, the European geographical context was favored and, given the comparability of this project with the Health and Retirement Survey (HRS) in the USA, studies carried out in North America were also included. Lastly, with regard to publication date criteria, the study focused on scientific works published in the period from 1980 to 2014. The temporal distribution of the 37 publications identified according to the stated criteria was not uniform. A total of $5.4 \%$ were included from the period between 1980 and 1990; 18.9\% covered the period between 1991 and 2000; 43.3\% represented the period between 2001 and 2010; 32.4\% were from the period between 2011 and 2014. The largest proportion of studies identified in recent years, or in other words since 2001, is due to the fact that scientific studies of social networks, with the identification of their morphological characteristics, only began in the second half of the 20th century, with scientific production on this theme intensifying from this period onwards ${ }^{8}$.

\section{Defining the fundamental concepts}

The concept of social networks emerged in Sociology and Social Anthropology in the 1930s and 1940s of the last century, and enjoys growing popularity today ${ }^{9}$. Mercklé ${ }^{9}$ considers a social network to consist of a set of social units and of the relationships between these social units, be they individuals or groups of individuals. The term social network used in this article designates a group of people or groups that are connected by some type of social relationship ${ }^{10}$.

There are two ways of approaching a social network: the direct approach and the indirect approach. In the indirect approach the researcher identifies the elements that are part of the social network of the respondent, through their social relationships. The mere existence of a social relationship authorizes the investigator to consider it significant. In contrast, in the direct approach to social networks, which is the approach preferred by the SHARE project, it is the respondents who identify the members of their social network they consider to be important.

The concept of QOL is also a fundamental concept in this work, although defining it is not an easy task. There is no consensus among researchers on the definition of the concept and the appropriate criteria to operationalize $\mathrm{it}^{11,12}$. The World Health Organization (WHO) approach is one of the most frequently observed in literature, defining QOL as the individual's perception of their position in life, in the context of the culture and value system in which they live and in relation to their goals, standards, expectations and concerns. The WHOQOL-OLD instrument, for use with the elderly, covers seven domains of QOL: sensorial functioning; autonomy; present, past and future activities; social participation; death and dying; intimacy; family ${ }^{13}$.

The approach in terms of satisfied/unsatisfied needs in the areas of control, autonomy, selfrealization and pleasure has also been highlighted by studies that feature the elderly as a target population ${ }^{14}$, and has been adopted by the SHARE project. In this approach, the Control, Autonomy, Self-Realization, Pleasure (CASP) scale is used to evaluate QOL in its CASP-12 or CASP-19 versions. Control consists of the capacity of an individual to intervene actively in their environment; while autonomy is a person's capacity to be free of the unwanted interference of other people ${ }^{15}$. The selfrealization and pleasure domains aim to capture the most active and reflexive dimensions of being an elderly person ${ }^{7}$. The diversity of approaches to measuring QOL does not allow for a single, universal definition of the concept. Given this impossibility, the approach in terms of satisfied/unsatisfied needs is chosen as adequate for the evaluation of the QOL of the elderly. This approach has advantages over the others. The CASP instrument for measuring QOL allows a multidimensional and global approach, rather than an assessment of only one domain 
of $\mathrm{life}^{16}$; has been validated for Europe and was specifically developed for use among the elderly. It is also an instrument that, unlike other measurement instruments, evaluates QOL and not the factors that influence it. In addition, CASP allows us to capture the more active and reflexive dimensions of the elderly (self-realization and pleasure), dimensions that have been ignored in many studies?

Considering that some researchers partially or totally overlap the concept of QOL with other concepts that refer to the notion of well-being, it was considered appropriate that this literature review should consider certain other indicators of wellbeing, as long as they refer to some of the dimensions of the concept of QOL. It should be noted that well-being in the elderly is a state that can result from a diversity of conditions, from physical health to subjective perception of $\mathrm{QOL}^{17}$.

Indicators of the level of well-being considered in this review include level of positive (includes positive indicators, such as joy, a good mood, happiness, calm) and/or negative affect (includes negative feelings felt by individuals such as sadness, nervousness, agitation $)^{18}$; level of depressive symptomatology (includes symptoms such as depressed mood, feelings of guilt, uselessness, impotence, hopelessness, sleep disturbances, and loss of appetite) ${ }^{19,20}$; level of selfesteem (cognitive evaluation of the person and of the self) ${ }^{21}$; level of anxiety (state of the individual who presents a catastrophic view of events, believing that something dangerous and threatening may happen $)^{22}$; physical health; health-related QOL (perception of mental and physical health, commonly measured by health-related quality of life assessment instruments such as SF-12 and SF-36); subjective health (perception or subjective appreciation of general health status); and general well-being, assessed through qualitative research techniques or Likert scales.

The levels of affect (positive and/or negative), depressive symptomatology, self-esteem and anxiety refer to the level of well-being at the psychological level, which is important for the satisfaction of needs in the pleasure and self-realization domains of QOL; physical health allows the satisfaction of the needs of the elderly in the areas of control and autonomy; The QOL related to health and subjective health refer to the level of satisfaction of needs in the areas of control, autonomy, pleasure and self-realization. The concept of general well-being is a comprehensive concept that can refer to any of the domains of the concept of QOL (control, autonomy, pleasure and self-realization).

Other indicators of well-being, such as satisfaction with life and happiness, were excluded because they were more subjective concepts and subject to rapid fluctuations/changes, unlike the other concepts considered, which express more constant conditions of individuals.

\section{RESULTS}

The 37 publications included in this literature review were analyzed according to the following categories: author(s)/year; local; methodology; sample representativeness; characteristics of the social network; measure of well-being; implementation of the well-being measure (Table 1). Five of the 37 results that composed the final sample of the integrative review carried out on the relationship between the social network and the well-being/QOL of the elderly person are described below. 
Table 1. Analysis grid with illustrative publications from literature review. Portugal, 2015.

\begin{tabular}{|c|c|c|c|c|c|c|}
\hline Author/Year & Location & Methodology & $\begin{array}{l}\text { Sample } \\
\text { representativity }\end{array}$ & $\begin{array}{l}\text { Characteristics } \\
\text { of social } \\
\text { network }\end{array}$ & $\begin{array}{l}\text { Well-being } \\
\text { measure }\end{array}$ & $\begin{array}{l}\text { Operationalization of } \\
\text { welfare measure }\end{array}$ \\
\hline $\begin{array}{l}\text { De Belvis } \\
\text { AG, Avolio } \\
\text { M, Spagnolo } \\
\text { A, Damiani } \\
\text { G, Sicuro L, } \\
\text { Cicchetti A et } \\
\text { al. (2008a) }\end{array}$ & Lazio, Italy & Quantitative & Yes & $\begin{array}{l}\text { Frequency } \\
\text { of contact; } \\
\text { geographical } \\
\text { proximity of } \\
\text { social network } \\
\text { elements }\end{array}$ & $\begin{array}{l}\text { Health-related } \\
\text { quality of life }\end{array}$ & SF-12 Questionnaire \\
\hline $\begin{array}{l}\text { Fiori KL, } \\
\text { Smith J, } \\
\text { Antonucci TC. } \\
(2007)\end{array}$ & $\begin{array}{l}\text { Berlin, } \\
\text { Germany }\end{array}$ & Quantitative & Yes & $\begin{array}{l}\text { Size of social } \\
\text { network; } \\
\text { frequency } \\
\text { of contact; } \\
\text { emotional } \\
\text { closeness }\end{array}$ & $\begin{array}{l}\text { Level of } \\
\text { depressive } \\
\text { symptomatology } \\
+ \text { physical health } \\
\text { (objective and } \\
\text { subjective) }\end{array}$ & $\begin{array}{l}\text { Hamilton Scale } \\
(1960)+\text { Overall } \\
\text { subjective assessment } \\
\text { of the present health } \\
\text { of respondents with } \\
\text { responses varying } \\
\text { from } 1 \text { (poor) to } \\
5 \text { (excellent) + no. } \\
\text { of serious chronic } \\
\text { diseases diagnosed } \\
\text { according to a } \\
\text { new review of the } \\
\text { "International } \\
\text { Statistical } \\
\text { Classification of } \\
\text { Diseases codes". }\end{array}$ \\
\hline $\begin{array}{l}\text { Hellström Y, } \\
\text { Andersson M, } \\
\text { Hallberg IR. } \\
(2004)\end{array}$ & $\begin{array}{l}33 \\
\text { municipalities } \\
\text { in southern } \\
\text { Sweden }\end{array}$ & Quantitative & Yes & $\begin{array}{l}\text { Size of social } \\
\text { network }\end{array}$ & Quality of life & $\begin{array}{l}\text { Life-quality Gerontology } \\
\text { Centre (LGC) scale (only } \\
\text { present quality of life e life } \\
\text { span quality) and SF-12. }\end{array}$ \\
\hline $\begin{array}{l}\text { Webb E, Blane } \\
\text { D, Mcmunn } \\
\text { A, Netuveli G. } \\
(2011)\end{array}$ & England & Quantitative & Yes & $\begin{array}{l}\text { Frequency } \\
\text { of contact; } \\
\text { emotional } \\
\text { closeness }\end{array}$ & Quality of life & CASP-19 Instrument \\
\hline $\begin{array}{l}\text { Zaninotto P, } \\
\text { Falaschetti } \\
\text { E, Sacker A. } \\
(2009)\end{array}$ & England & Quantitative & Yes & $\begin{array}{l}\text { Type of } \\
\text { relationship; } \\
\text { emotional } \\
\text { closeness }\end{array}$ & Quality of life & CASP-19 Instrument \\
\hline
\end{tabular}

Scientific literature on the impact of social networks on the QOL/well-being of the elderly

Some specific characteristics of the social network are considered nuclear: the size of the social network; the type of relationship; the frequency of contact; the geographical proximity of the elements of the social network and emotional proximity. Litwin and Stoeckel ${ }^{23}$ constructed a social network indicator based on these characteristics of the network of confidants (members of the social network considered by the individual/respondent as important, and with whom they often talk about matters that are important to them, such as worries or positive events they have experienced). An analysis of the main components allowed the authors to propose an index that takes into account these five characteristics. 
It should be noted that not all the investigations allowed conclusions to be drawn about cause and effect relationships, meaning it was only possible to verify if there was an "association" between certain social network characteristics and the QOL/ well-being of the elderly. Only three of the studies analyzed were longitudinal ${ }^{24-26}$, with the remaining cross-sectional in design, making it impossible to establish causality between the networks and the QOL/well-being of the elderly.

\section{Size of social network and QOL/well-being}

With regard to the size of the social network, it is known that, with advancing age, the social networks of the elderly tend to be smaller ${ }^{4}$. This reduction in the size of social networks with age can be explained by the death of people close to the elderly person, health problems, children leaving home and by events that deprive the elderly of their social networks at work, but also by the theory of social-emotional selectivity. Such a theory postulates that elderly persons become increasingly aware of the limitations of the future time available to them and are motivated to be more selective in choosing social partners, favoring emotionally significant relationships over more peripheral ones ${ }^{27}$.

The size of social networks has been, in general,

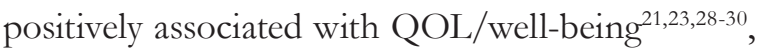
both in European countries and in North America. However, some investigations carried out in European countries show that there is no association between the size of the social network and QOL ${ }^{31,32}$. According to Bowling and Gabriel31, individuals value social support and the emotional closeness that relationships can provide them more than the size of the network.

In summary, much of the literature indicates that larger networks are associated with greater well-being among the elderly population ${ }^{21,23,28-30}$. It should be noted that, in general, the social networks of the elderly are small, and this may be associated with a low quality of life/well-being among these individuals. However, this data should be read in conjunction with the following information regarding the impact of other characteristics of the social network on QOL.
Type of relationship and QOL/well-being

The type of relationship also seems to influence well-being, with friendship and neighborhood networks documented as having a more positive effect than family networks ${ }^{21,33-35}$, given the voluntary nature of the former in contrast to the latter ${ }^{35}$. In addition, as advocated by Larson et al. ${ }^{34}$, referring to a study of the elderly in Canada, activities performed with family members are usually routine, while the time spent with friends is commonly devoted to activities based on common interests and characterized by spontaneity. According to Pinquart and Sörensen ${ }^{21}$, friends are often members of the same age group, sharing personal characteristics, experiences and lifestyles. Another potential motive, argued by Cheng et al. ${ }^{33}$ based on a review of the literature, is that negative interactions are more frequent among family members than among friends. In addition, conflict with family members can have a highly negative effect on the well-being of the elderly, since the bonds established with family members cannot be easily undone ${ }^{6}$.

On the other hand, studies in Europe and North America have shown a positive contribution or association between more than one type of relationship at the same time (e.g. relations with spouse and children, concomitant with relations of friendship with individuals outside the family) and QOL/well-being 23,26,36,37.

\section{Geographic proximity of social network and QOL/well-being.}

Literature on the relationship between the geographic proximity of the social network and the QOL/well-being of the elderly is scarce. In the restricted set of studies in which this analysis is carried out, the works by De Belvis et al. ${ }^{38,39}$ in Italy show that there is a positive association between the geographic proximity of the family network and the health-related QOL of elderly persons aged 60 or over, controlling the effect of sociodemographic and health variables. The results presented by Litwin and Stoeckel ${ }^{37}$, based on data from the fourth wave of the SHARE project, on individuals aged 65 and over in 16 European countries, indicate that low or moderate geographical proximity of social network elements is associated with the greater QOL of these individuals, 
once the effect of sociodemographic variables and the state of health is controlled. Such control is necessary to avoid cases in which geographical proximity is a choice of families with elderly people needing care and who therefore have a lower QOL. It is not possible to give a satisfactory explanation of this discrepancy in the results. Moreover, with the reduced number of studies, it is not possible to identify any pattern or trend regarding the relationship between this characteristic of the social network and the well-being of the elderly.

Frequency of contact and QOL/well-being.

Frequency of contact is one of the most commonly used indicators to describe interaction. High contact frequencies have been commonly associated with higher levels of QOL or other indicators of well-being in North America and European countries ${ }^{21,29,38-41}$. However, some studies have associated frequency of contact with lower wellbeing ${ }^{42}$ or have concluded that there is no association between contact frequency and the QOL/well-being of the elderly ${ }^{7,31,43,44}$. Distinguishing between contact with family and with friends, Netuveli et al. ${ }^{5}$ detected a positive association between the frequency of contact with friends and QOL and, contrastingly, a negative association between the frequency of contact with family members and QOL. Similarly, based on data from a longitudinal study, Webb et al. ${ }^{25}$ found that the QOL of elderly residents in England was positively associated with the frequency with which they contacted their friends, whereas, on the contrary, a high frequency of contact with family members reduced QOL. It is likely that the explanations for this difference between contact with family and contact with friends are those already mentioned in the previous section on the type of relationship and QOL/well-being.

Despite some discrepancy in results, which may be due to the different geographical contexts and samples, and to different ways of operationalizing the concept of well-being in the surveys discussed, the results suggest a positive association between frequency of contact and well-being. It is possible that with the tendency for the size of the social network to reduce in old age, due in particular to the death of peers, contact with the elements that make up this network is of greater significance and importance for the elderly, making frequency of contact with the social network positive for their well-being. However, it can also be assumed, conversely, that elderly persons with greater well-being establish more contacts precisely because they feel well.

\section{Emotional closeness and QOL/well-being.}

Emotional closeness is a feature of the social network that has been operationalized in different ways: as the degree of emotional proximity of the elderly person to the members of their social network ${ }^{37}$ or as the number of emotionally close people 5 .

Overall, one can say that a high degree of emotional closeness has been associated with high levels of QOL/well-being in old age a, $^{5,21,25,26,37}$. The theory of social-emotional selectivity, already mentioned in this article, contributes to explaining the positive contribution of emotional closeness to the well-being of the elderly. This theory of socialemotional selectivity derives from the theory of compensatory optimization 45 , which also allows us to understand these results. According to this model, optimization means the acquisition, application, coordination and maintenance of internal and external resources involved in achieving higher levels of functioning, while compensation implies the adoption of alternatives to maintain functioning46. In fact, elderly persons can compensate for agerelated social barriers and optimize their social interactions by focusing their limited time and energy on a few social partners who are better able to meet their main social needs ${ }^{27}$.

\section{DISCUSSION}

The present review of scientific literature on the relationship between social networks and QOL or other indicators of well-being for elderly persons has identified several trends related to methodological content. These tendencies relate to approaches to and the operationalization of QOL, as well as to results regarding the relationship between the characteristics of social networks and QOL/well-being in old age.

In terms of methodology, the general use of quantitative methodology of social research is notable, with much less use made of qualitative methodology 
or a combination of the two. The samples that have been employed tend to be made up of more than 30 individuals, while more than half of the studies analyzed in this review ${ }^{7,25,26,29,30,37,38,42}$ made use of representative samples. Thus, probabilistic selection of the elements to be studied within a determined temporal and geographical context was preferred.

The concept of QOL has been approached and operationalized in a variety of ways. It is fair to say, however, that regardless of how the concept of QOL is defined and operationalized in each study, research has consistently demonstrated the beneficial effect of social and family relationships, and therefore social networks, on the QOL/well-being of elderly persons.

Regarding the relationship between the characteristics of social networks and QOL/wellbeing in old age, it has been observed that: a) in general, the size of a social network has been positively associated with the QOL/well-being of elderly persons, although some studies show that there is no association between these factors; $b$ ) overall, literature has found evidence that networks of friends contribute more to the QOL/well-being of elderly persons than those made up of family members, while the positive contribution of enjoying more than one type of relationship (for example, the joint importance of relations with friends and with neighbors) was also noted; c) the low number of studies on the impact of the geographic proximity of a social network on QOL/well-being in old age does not allow the identification of any pattern or trend regarding the effect or influence of this characteristic; d) in general, frequency of contact is positively associated with the well-being of elderly persons, although some studies indicate that there is no association between the variables; e) literature clearly indicates a positive association between emotional closeness with elements of social networks and the QOL/well-being of elderly persons.

The discrepancy in the results observed is possibly due to the use of different samples, which are based on cross-sectional analyzes rather than longitudinal surveys, making it impossible to establish relations of cause and effect between social networks and wellbeing $^{47}$, as well as the different geographical contexts and distinct ways of defining and operationalizing QOL/well-being employed. Discussion among researchers regarding the definition of QOL and ways to operationalize this measure would greatly help to mitigate these differences and add rigor to scientific research on this subject. In fact, researchers often do not define the concept of QOL in their publications and rarely justify the selection of the measuring instrument they use, resulting in a proliferation in the number of approaches to the operationalization of the concept.

Other omissions have been identified in the level of scientific knowledge on this subject. Firstly, associations between the characteristics of social networks and QOL/well-being have been demonstrated, but researchers seldom investigate the factors that lead to these associations. Secondly, there is a lack of longitudinal studies that would enable causality between the characteristics of social networks and QOL/well-being to be established. Thirdly, there is a clear lack of studies on more specific elderly populations, such as those living alone or those residing in rural areas. Although the proportion of people living alone in European societies has grown considerably in the last four decades ${ }^{48}$, becoming an increasingly common behavioral pattern among elderly persons on the continent ${ }^{49}$, there is a lack of research focusing on this population.

The limitations of the present literature review derive from the criteria used in the selection of bibliographic material: the fact that studies based on research carried out in Europe and North America have been prioritized, as well as the selection of only some of the characteristics of social networks, namely those considered nuclear ${ }^{23}$.

Nevertheless, analysis of the studies considered in this article shows how the concept of QOL has been defined and operationalized and evidences the latest research on the relationship between the main characteristics of the social networks of elderly persons and their QOL. This analysis could be used by students and researchers interested in this subject, as well as contributing to the formulation of public policies aimed at improving the quality of life of elderly persons. 


\section{CONCLUSION}

Scientific literature shows that networks of friends contribute more than family networks to the quality of life/well-being of elderly persons. The positive contribution of having more than one type of relationship (e.g. simultaneous friendship and family relationships) to the quality of life/well-being of elderly persons has also been demonstrated. Finally, the studies analyzed indicate the positive impact of emotional closeness on quality of life/well-being.

The present literature review allows us to make suggestions for the development of future research. Firstly, it is necessary to prioritize longitudinal analyzes, given their scarcity. It is also important to make use of a combination of quantitative and qualitative methodologies. On one hand, quantitative methodologies make it possible to work with large and

\section{REFERENCES}

1. Bosworth HB, Schaie KW. The relationship of social environment, social networks, and health outcomes in the Seattle Longitudinal Study: Two analytical approaches. J Gerontol Ser B Psychol Sci Soc Sci 1997;52(5):197-205.

2. Martin M, Grünendahl M, Martin P. Age differences in stress, social resources, and well-being in middle and older age. J Gerontol Ser B Psychol Sci Soc Sci 2001;56(4):214-222.

3. Bowling A, Gabriel Z, Dykes J, Dowding LM, Evans $\mathrm{O}$, Fleissig A, et al. Let's ask them: a national survey of definitions of quality of life and its enhancement among people aged 65 and over. Int J Aging Hum Dev 2003;56(4):269-306.

4. Cornwell B, Laumann EO, Schumm LP. The social connectedness of older adults: a national profile. Am Sociol Rev 2008;73(2):185-203.

5. Netuveli G, Wiggins RD, Hildon Z, Montgomery SM, Blane D. Quality of life at older ages: evidence from the English longitudinal study of aging (wave 1). J Epidemiol Community Health 2006;60(4):357-63.

6. Krause N. Social Support. In: Binstock RH, George LK, Editores. Handbook of Aging and the Social Sciences. San Diego: Academic Press; 2001. p. 272-94.

7. Wiggins RD, Higgs PFD, Hyde M, Blane DB. Quality of life in the third age: key predictors of the CASP-19 measure. Ageing Soc 2004;24(5):693-708. representative samples, while on the other, qualitative methodologies make it possible to deepen, enrich, and explain/understand the information collected using quantitative methodology on the associations/ effects of social networks on quality of life. Finally, given the scarcity of verified information, more research should be done on specific populations, with particular emphasis on elderly persons living alone.

\section{ACKNOWLEDGEMENTS}

We are grateful for the support of the Fundação para a Ciência e Tecnologia (Foundation for Science and Technology) (FCT), who awarded one the authors of this work with a PhD scholarship under QREN-POPH-Typology 4.1-Advanced Training, supported by the European Social Fund and Brazilian Ministry of Education funding.

8. Portugal S. Contributos para uma discussão do conceito de rede na teoria sociológica. Oficina CES 2007;271:1-35.

9. Mercklé P. Sociologie des réseaux sociaux. Paris: La Découverte; 2004.

10. Matheus RF, Silva ABO. Análise de redes sociais como método para a Ciência da Informação. Rev Ciênc Inf [Internet] 2006 [acesso em 10 set 2012];7(2):72-93. Disponível em: http://www.dgz.org. br/abr06/F_I_art.htm.

11. Farquhar M. Definitions of quality of life: a taxonomy. J Adv Nurs 1995;22(3):502-8.

12. Fayers P, Machin D, editors. Quality of life: the assessment, analysis and interpretation of patientreported outcomes. Chichester: Wiley; 2007.

13. THE WHOQOL GROUP. The World Health Organization quality of life assessment (WHOQOL): position paper from the World Health Organization. Soc Sci Med 1995;41(10):1403-9.

14. Hyde M, Wiggins RD, Higgs P, Blane DB. A measure of quality of life in early old age: the theory, development and properties of a needs satisfaction model (CASP-19). Aging Ment Health 2003;7(3):186-94.

15. Patrick BC, Skinner EA, Connell JP. What motivates children's behavior and emotion? Joint effects of perceived control and autonomy in the academic domain. J Pers Soc Psychol 1993;65(4):781-91. 
16. Wiggins RD, Netuveli G, Hyde M, Higgs P, Blane D. The evaluation of a self-enumerated scale of quality of life (CASP-19) in the context of research on ageing: a combination of exploratory and confirmatory approaches. Soc Indic Res 2008;89(1):61-77.

17. George LK. Still happy after all these years: research frontiers on subjective well-being in later life. J Gerontol Ser B Psychol Sci Soc Sci 2010;65(3):331-9.

18. Keyes CLM. The exchange of emotional support with age and its relationship with emotional wellbeing by age. J Gerontol Ser B Psychol Sci Soc Sci 2002;57(6):518-25.

19. Radloff LS. The CES-D Scale: a Self-Report Depression Scale for Research in the General Population. Appl Psychol Meas 1977;1(3):385-401.

20. Underwood M, Lamb SE, Eldridge S, Sheehan B, Slowther AM, Spencer A, et al. Exercise for depression in elderly residents of care homes: a cluster-randomised controlled trial. Lancet 2013;382(9886):41-9.

21. Pinquart M, Sörensen S. Influences of socioeconomic status, social network, and competence on subjective well-being in later life: A meta-analysis. Psychol Aging 2000;15(2):187-224.

22. De Oliveira KL, Dos Santos AAA, Cruvinel M, Néri AL. Relação entre ansiedade, depressão e desesperança entre grupos de idosos. Psicol Est 2006;11(2):351-9.

23. Litwin H, Stoeckel KJ. Engagement and social capital as elements of active ageing: an analysis of older europeans. Sociol Politiche Sociali 2014;17(3):9-31.

24. Huxhold O, Fiori KL, Windsor TD. The Dynamic Interplay of Social Network Characteristics, Subjective Well-Being, and Health: the costs and benefits of socio-emotional Selectivity. Psychol Aging 2013;28(1):3-16.

25. Webb E, Blane D, Mcmunn A, Netuveli G. Proximal predictors of change in quality of life at older ages. $J$ Epidemiol Community Health 2011;65(6):542-7.

26. Zaninotto P, Falaschetti E, Sacker A. Age trajectories of quality of life among older adults: results from the English Longitudinal Study of Ageing. Qual Life Res 2009;18(10):1301-9.

27. Fung HH, Carstensen LL, Lang FR. Age-related patterns in social networks among European Americans and African Americans: implications for socioemotional selectivity across the life span. Int J Aging Hum Dev 2001;52(3):185-206.

28. Farquhar M. Elderly people's definitions of quality of life. Soc Sci Med 1995;41(10):1439-46.
29. Fiori KL, Smith J, Antonucci TC. Social network types among older adults: a multidimensional approach. J Gerontol Ser B Psychol Sci Soc Sci 2007;62(6):322-30.

30. Hellström Y, Andersson M, Hallberg IR. Quality of life among older people in Sweden receiving help from informal and/or formal helpers at home or in special accommodation. Heal Soc Care Community 2004;12(6):504-16.

31. Bowling A, Gabriel Z. Lay theories of quality of life in older age. Ageing Soc 2007;27(6):827-48.

32. Jakobsson U, Hallberg IR, Westergren A. Overall and health related quality of life among the oldest old in pain. Qual Life Res 2004;13(1):125-36.

33. Cheng ST, Li K, Leung EMF, Chan ACM. Social exchanges and subjective well-being: do sources of positive and negative exchanges matter? J Gerontol Ser B Psychol Sci Soc Sci 2011;66(6):708-18.

34. Larson R, Mannell R, Zuzanek J. Daily well-being of older adults with friends and family. Psychol Aging 1986;1(2):117-26.

35. Paúl C. Envelhecimento activo e redes de suporte social. Sociologia 2005;25:275-87.

36. Litwin H, Shiovitz-Ezra S. Social network type and subjective well-being in a national sample of older Americans. Gerontologist 2011;51(3):379-88.

37. Litwin H, Stoeckel KJ. Confidant network types and well-being among older europeans. Gerontologist 2013:1-11.

38. De Belvis AG, Avolio M, Spagnolo A, Damiani G, Sicuro L, Cicchetti A, et al. Factors associated with health-related quality of life: the role of social relationships among the elderly in an Italian region. Public Health 2008;122(8):784-93.

39. De Belvis AG, Avolio M, Sicuro L, Rosano A, Latini E, Damiani G, et al. Social relationships and HRQL: a cross-sectional survey among older Italian adults. BMC Public Health [Internet] 2008 [acesso em 14 fev. 2014];8(348):1-10. Disponível em: http://www. biomedcentral.com/1471-2458/8/348

40. Litwin H, Stoeckel KJ. Social networks and subjective wellbeing among older Europeans: does age make a difference? Ageing Soc 2013;33(7):1263-81.

41. Scott JP, Butler MH. Subjective well-being of rural adults 75 years of age or older: a longitudinal evaluation. Fam Consum Sci Res J 1997;25(3):251-68.

42. Litwin H. Social Networks and Well-being: a comparision of older people in mediterranean and non-mediterranean countries. J Gerontol Ser B Psychol Sci Soc Sci 2009;65(5):599-608. 
43. Newsom JT, Schulz R. Social support as a mediator in the relation between functional status and quality of life in older adults. Psychol Aging 1996;11(1):34-44.

44. Ward RA. Multiple parent-adult child relations and well-being in middle and later life. J Gerontol Ser B Psychol Sci Soc Sci 2008;63(4):239-47.

45. Baltes PB, Baltes MM. Psychological perspectives on successful aging: The model of selective optimization with compensation. In: Baltes PB, Baltes MM, Editores. Successful Aging: Perspectives from the behavioral sciences. New York: Cambridge University Press; 1990. p. 1-34.
46. Neri AL. O legado de Paul B. Baltes à psicologia do desenvolvimento e do envelhecimento. Temas Psicol 2006;14(1):17-34

47. D'Orsi E, Xavier AJ, Ramos LR. Trabalho, suporte social e lazer protegem idosos da perda funcional: Estudo Epidoso. Rev Saúde Pública 2011;45(4):685-92.

48. Mauritti R. Viver só: mudança social e estilos de vida. Lisboa: Editora Mundos Sociais; 2011.

49. Gierveld J, De Valk H, Blommesteijn M. Living arrangements of older persons and family support in more developed countries. Haia: Netherlands Interdisciplinary Demographic Institute; 2000. 